\title{
Developing Mathematical Literacy through project work: A teacher/teaching perspective ${ }^{1}$
}

\author{
Renuka Vithal \\ Faculty of Education, University of KwaZulu-Natal \\ vithalr@ukzn.ac.za
}

The implementation of the new Mathematical Literacy curriculum in South Africa is assuming several different conceptions of mathematics and therefore also being realised through a range of different pedagogies. In this paper I begin from a particular privileging of a critical perspective in mathematics education, which I argue is one (among others) of the forces shaping the new South African curriculum reforms, particularly the Mathematical Literacy curriculum. If so, then the case for a specific pedagogy, that of project work, can be shown to support the development of a mathematical literacy from a critical perspective. In this paper a particular set of conceptual tools, principles and practices associated with project work, as developed in the Scandanavian context but researched in South Africa, are elaborated from the perspective of teachers/teaching of mathematical literacy.

\section{Mathematical literacy from a critical perspective}

Arguably, many of the intentions in the critical, developmental and learning outcomes enunciated in the new Mathematical Literacy South African curriculum policy document (Department of Education, 2003) resemble those embodied in the broad emerging literature that explores the social, cultural, political, historical and economic dimensions of mathematics education, both as a field of practice and as a field of study. That is to say that a particular interpretation being made in this paper of mathematical literacy is one that is more closely aligned to that from a critical perspective.

The notion of a "critical mathematics literacy", first used in the early ' $80 \mathrm{~s}$, sought to link in a more direct way concerns in mathematics education with a critique of society (see for example Frankenstein, $1987 ;$ 1990). But here too the concepts and terms are contested as is the very idea of combining mathematics with literacy. Skovsmose (1994), for instance, has coined the term mathemacy, which he argues brings together both a democratic competence and a critical competence in mathematics education. Mathemacy as an integrated competence "implies that the guiding principles for mathematics education are not any longer to be found in mathematics but in the social context of mathematics" (Skovsmose, 1994: 117). One of the means for achieving this kind of mathematical literacy that has been particularly well demonstrated in the Scandanavian context is through project work (see also Mellin-Olsen, 1987). It is this specific theorising and practices of project work, but taught and researched in the South African context in my own work with student teachers and learners, that inspires its exploration in this paper as a means for achieving a particular kind of mathematical literacy - one that allows for a critique of society in strengthening democracy. Such a conception of mathematical literacy seeks to provide students with opportunities to begin to "read the world (understand complex issues involving justice and equity) using mathematics, to develop mathematical power, and to change their orientation toward mathematics" (Gutstein, 2003: 37). Whatever the terms - numeracy (in the UK see Brown, 2003) or quantitative literacy (in the USA see Steen, 2001) - an emerging concern is with linking knowledge, skills, attitudes and values produced through mathematics literacy to those needed for effective participation in democratic life in the 21 st century.

\footnotetext{
${ }^{1}$ A version of this paper was presented as a keynote address: Vithal R. (2006) Developing Mathematical Literacy through Project Work, in Harikirat S. et al. (eds) Shaping the Future of Science, Mathematics and Technical Education. Proceedings of $11^{\text {th }}$ Annual Conference of the Sultan Hassanal Bolkiah Institute of Education, Universiti Brunei Darussalam, 22-25 May, pp. 117-128.
} 


\section{Project work}

Project work is a well established pedagogy but it may be engaged from many different theoretical orientations and practised in different ways within mathematics education (see as an example Boaler, 1997). According to the Third International Mathematics and Science Study (TIMSS, 1999) a substantial number of South African teachers claim to engage project work (Mullis et al., 2000). The mathematics teachers of approximately $40 \%$ of learners surveyed (the third highest of 38 countries), stated that they sometimes or always assigned mathematics homework based on small investigations and individual or small group investigations compared to the international average of $18 \%$. In this conception of project work, it is primarily used as a continuous assessment practice rather than as a classroom pedagogy per se. That is, it usually involves a small self-study on a topic or problem selected by the teacher to be done outside class-time. However, in this paper quite a different conception of project work is being explored.

The particular conception of project work as a substantial classroom pedagogy, specifically from a critical perspective, is perhaps most well developed both in theory and practice in the Scandinavian context (see Olesen \& Jensen, 1999). Problem orientation, participant directed, interdisciplinarity, and exemplarity are central conceptual tools in this practice of project work. This more "progressive" and "open" project work pedagogy, in which learners take greater responsibility for their learning while working on problems that are jointly negotiated with their teachers, has been explored and researched with respect to all levels of school mathematics (Skovsmose, 1994; Christiansen, 1996; Nielsen et al., 1999; Vithal, 2003; 2004; 2005) and also university mathematics (Vithal, Christiansen \& Skovsmose, 1995; Niss, 2001).

In this paper this set of conceptual tools and practices for developing a mathematical literacy from a critical perspective is extended to include assessment and practical organisation. These are argued from a teacher/teaching perspective as being necessary (but by no means sufficient) to sustain and make project work viable in a mathematics classroom. While this practice of project work offers a means for a different kind of mathematical literacy to develop, it also produces particular tensions. Each of these six conceptual tools and their associated practices are discussed in the rest of this paper with reference to a range of projects undertaken in diverse South African mathematics classrooms.

\section{Problem Orientation}

A key foundational principle in this conception of project work is that the curriculum experience is not organised around the structures of the discipline of mathematics but rather around some critical problem, question or theme related to the context of the school, community or broader society and that is deemed important by the learners. Learner interest in the problem is therefore a critical feature of learning because it shapes how they would invest in dealing with the problem and take ownership (Skovsmove \& Nielsen, 1996). In her work with young learners in grade 6, Paras (1998) reports how learners chose a topic of building a fence around a section of the school ground to prevent their balls from rolling down an embankment during play time over a project on solving the problem of a traffic jam each morning at the entrance to the school grounds. They argued that the second was an adult problem and not really a concern for them. However, the kinds of problems that are chosen need not be rooted in reality. Projects can also be selected for challenging learners' imagination such as creating a dream playground which was implemented in one school with poor facilities for the learners (Vithal et al., 1997).

Learning as action, which underpins project work, implies that students must own the reason for learning and cannot be forced to be critical. In practice, according to Skovsmose (1994), this means that any topic, issue or problem that is selected has to be known by the broad range of learners; belong to their daily life; be interesting and important to learners; can be described in nonmathematical terms; allow them to develop a personal in-depth understanding of the multifaceted aspects of the chosen focus; and allow mathematical ideas, skills and concepts to emerge. However, inherent in this freedom to choose is the tension of the authority of the teacher to teach mathematics. For example, learners often chose topics in which it was difficult to see any mathematical potential, such as interviewing sports personalities. Even when topics were chosen with possible mathematical potential these would be subverted by learners away from mathematics and the teacher's intervention was required to keep the mathematics in view. So the freedom to choose exists in a kind of contradiction but also cooperates with the structure of the discipline and the 


\section{Renuka Vithal}

classroom and the obligation to teach mathematics, even if it is a contextualised mathematics.

Teacher interests are constantly in tension with learner interests when classrooms themselves are construed as democratic spaces. For example, a project that learners chose in order to question the school about inadequate and under-utilisation of sporting facilities was (re)directed by the teacher toward a survey. The survey, however, became a minor aspect as learners pursued other activities to make a case for their complaint. But in this the "failure" of a project can also be seen as its "success" if a broader view of learning mathematics is taken. What learners learn through constituting the class as a democratic space is how they can have voice, and how that voice could challenge authority to meet their educational needs. An important aspect that emerges here is in how freedom and democracy coexist with structure and authority in any classroom that enacts this kind of approach to project work (Vithal, 2003). These play out in a productive tension that provides learners with opportunities to understand societal conditions and features that they are expected to become aware of in acquiring a mathematical literacy.

\section{Participant directed}

The notion of being participant directed refers to the democratised relationship and responsibilities for the work in the project as being jointly undertaken by both teachers and learners. Learners and teachers share ownership for the processes, activities and the direction the project takes. In this co-construction of the project is a recognition of different knowledge, skills, abilities and vested interest between learners and teachers, and among the learners themselves involved in any one project. Typically project work is undertaken in groups and the diversity in the group often means that compromises are made in agreeing to do a particular project. The participant directed nature of project work within groups makes it important for the project to provide entry to and engagement with the problem or topic at a number of different levels and for different capacities and talents. In a project on "how much is spent on our education" learners in any one group all contributed different resources to create a chart representing their different graphs of parental expenditure. They debated over several days how to represent the lists of costs their parents incurred for their schooling in different types of bar graphs or pie graphs.

Here what was observed was that learners tended to choose what they deem to be easier and hence they chose to draw bar graphs. But what was also observed was a strong teacher intervention. Graph drawing was first attempted by learners with reference to a mathematical text that they were given by the teacher. Only later was a lesson conducted by the teacher on how to draw these graphs when other groups also chose this mathematical representation for their project - for example a group investigating the problem of too much homework who were listing how they spent their time after school. The participation of the teacher as a facilitator in this conception of project work includes not abdicating her responsibility and obligation to provide access to her knowledge and skills resource base to her learners.

Whether a single project is undertaken by a whole class with different activities delegated to different groups (as was the case in the fence building project by Paras, 1998) or multiple projects are undertaken by different groups in the same class, projects allow for different capacities and talents to find expression in relation to the mathematics. For example, in the sports project investigating the problem of inadequate facilities, some learners interviewed the school principal and physical education teacher about this while others solicited information about sporting preferences among the learners in the class. In being activity or task based and multiple participant directed, the different abilities and interests of learners assisted them to investigate and understand a particular problem from multiple perspectives. But as in all team efforts there were debates in different groups about the differential participation of some members and learners had to deal with members not doing their work, marginalising and silencing.

In South Africa, given our apartheid history, differences along race, gender and class dimensions often get played out in much sharper tensions as learners from still deeply segregated residential areas with huge differences in access to basic resources in their home settings come together in a classroom to discuss societal problems. The tension here is in how difference is left unchecked to sow divisions and more conflicts or is actively worked with and valued as diversity which is recruited to deeper understanding and possible actions on the inequalities of societies to move toward equity. The contextualised nature of mathematical literacy within a project work pedagogy opens for engagement with this broader integrated mathematical competence. In real terms this means legitimately raising questions in a mathematics classroom, for instance, about the gendered nature of work. In an activity of 


\section{Developing Mathematical Literacy through project work: A teacher/teaching perspective}

measuring the ground, observed in two different schools during project work, boys were found refusing to allow girls to use measuring instruments such as builders' tapes, which required strong intervention from the teacher and a discussion about the South African constitution and the rights of women (Paras, 1998; Vithal, 2005).

The point is that diversity is in fact required to bring to the surface issues of equity so that they can be engaged. Mathematical literacy carries the potential for developing critical "pupil-citizens" who gain the experience of working with and in diversity, which can be carried to broader societal settings. Learners learn through and with mathematics the "language of decision-making" (Nielsen et al., 1999: 15) as a project unfolds and different participants together with the teachers push the project in different directions. To engage effectively in collective work within different kinds of group settings, to organise and manage themselves responsibly, is an important critical outcome identified in the new curriculum.

\section{Interdisciplinarity}

Definitions of mathematical literacy assume a contextualised mathematics. This contextualisation refers on the one hand to links with reality (whether past, present or future) and assumes on the other hand that any exploration of a topic or theme will require connections with other subject areas. If the starting point for a project is not some narrow mathematical content to be learnt, "interdisciplinarity implies drawing on different disciplines to the extent that they are useful for the treatment of a specific problem" (Vithal et al., 1995). The problem oriented aspect of project work which argues for choice in problem selection and seeks societal relevance entrenches interdisciplinarity, which recognises the separation of disciplines but equally takes into account their relations and intersections toward a synthesis of knowledge and skills needed to better understand the same object of study from different perspectives and points of view (Bastos \& Costa, 2000). In a project on redesigning the agricultural science garden and in the fence building project, the teachers saw the need to link with work being done in geography on scale drawings.

Project work opens real possibilities for linking mathematics in authentic ways to other subjects but this requires effort and facilitation on the part of the teacher. The English language teacher was asked to help the learners in the fence building project to write a letter to the department about assistance with funds. The question of what mathematics should be included in the letter and how it should be represented was discussed. The letter that was eventually chosen came from a group who were considered "weak" performers in mathematics but who had incorporated all the key information. This demonstrates how a broader conception of mathematics and what counts in being regarded as being good at it can be widened in mathematical literacy achieved through project work.

Integration and progression in the disciplines that takes account of learners' knowledge and skills at their grade level is made possible in this conception of project work. In both the projects on redesigning the agricultural science garden and the fence building one, learners had to undertake the task of measuring the perimeter in appropriate units, using different measuring instruments in groups, agreeing in the group on discrepancies in readings and measures, recording this information, making conversions and operating on this in decimals and representing the data in scale drawings. Different levels of competence and areas of background knowledge and skills were brought together as these tasks were undertaken. In this way project work gives learners with other interests and strengths a different entry into mathematics. Teachers remarked on how learners who did poorly in mathematics or showed a fear or dislike for the subject in the traditionally taught mathematics class, were showing improved performance in mathematics in this approach. That is, valuing their other strengths seemed to have a positive impact on their mathematics both in achievement and attitude (Vithal, 2004; 2005).

The strength of any interdisciplinary approach rests on the strengths of the particular disciplines. Once learners decided or were guided into a particular activity and were given a reasonable opportunity to demonstrate their capacity to undertake the task, teachers intervened with direct exposition teaching if necessary. For instance, lessons were taught on how to draw bar graphs when it became clear several learners were struggling with identifying the scales on the $\mathrm{x}$ - and $y$-axis and representing the information from their respective projects. The difference in this kind of exposition teaching from traditional teaching is that the teacher is working from learners' data and the reasons for learning belong much more strongly to learners than to the teachers.

A particular challenge in the teaching and learning of a contextualised mathematics, is that the teacher has to ensure that neither learners' 


\section{Renuka Vithal}

understanding of the mathematics or that of the context gets compromised. When the learners in the fence building project called the different companies on quotes for different types of fencing and forgot to ask for the sales tax (Value Added Tax of 14\%), some discussion ensued about whether they should call the companies back to get the information or work it out themselves. A lesson was conducted by the teacher on percentages using the given quotes which allowed them to check the costs and discover their budget was inadequate.

This interdisciplinary aspect of project work brings to the fore a different power of knowing mathematics. It makes visible in a direct and explicit way where and how mathematics and its systematisation is used and can be used in relation to the problem or topic being investigated. Much of mathematics is taught assuming that learners can and will be able to make these connections. In fact even when explicitly taught, they were often not made. Most of the letters that were drafted to send to the Department of Education for support with funds to build the fence made no reference to the perimeter, metered costs, etc. until this was brought to learners' attention. When making a case to the principal about the lack or provision and under-utilisation of the existing sporting facilities by the sports project group, the survey of learner preferences was not completed or presented as evidence to counter the school's reasons of timetabling and space. Being able to use mathematics accurately and effectively to improve their own life conditions both inside and outside school add and create much more powerful reasons for learners to learn and succeed in mathematics other than to gain good grades and for access to further educational opportunities.

\section{Exemplarity}

The exemplarity principle is central to justifying an alternative project-based curriculum and has been interpreted for a critical mathematical literacy in the work of Skovsmose (1994). It deals with a different approach to curriculum selection that argues for "exemplification" rather than "coverage" (Bishop, 1988). The main idea is that some larger totality or complexity can be reflected in and comprehended by focusing on some smaller part of it, a particular problem or phenomenon. By working on a single problem, opportunities may be created for developing knowledge, skills, attitudes and values for understanding the topic in a broader context of society and of the disciplines themselves. Construing learners as epistemic subjects interested to know their world and to act meaningfully in it to improve their situation, requires that the curriculum is organised so that its subject matter is relevant and meaningful from the perspective of individual experience and relevant to a conceptual understanding of society (Rasmussen, 1991). By working on a single problem of "how much money is spent on my education" learners had the possibility to come to know multiple realities. They came to know their family reality of how much parents sacrificed to pay for their school needs, and the reality of the school that was trying to address multiple competing needs for a school library, hall and sporting facilities. However, they left unexplored the national reality of the broader education funding system inherited from apartheid with its still continuing deep inequalities.

Each project carries a range of potentialities that open for exploring different realities and complexities. In actuality a limited number are engaged by virtue of the directions the different participants pursue and their vested interests. The focus on learner interest may be linked to the notions of foregrounds and backgrounds of the participants in any project, which comes to shape what becomes part of actuality and what remains as potentiality. Foregrounds, according to Skovsmose (1994), refers to those possibilities that a social situation reveals to an individual. For learners in school the social situation seldom went beyond the totality of the school to national issues and imperatives. In seeking to address the problem of high schools fees, learners did question and come to know the broader system of education funding. However, focusing on potentialities and actualities we can come to understand not what projects fail to do but rather what they do for particular reasons.

The extent to which the project is pushed into different realities such as into the broader community or even developing a national or global perspective depends on the dynamics of particular groups engaged in a project and the role and orientation of the teacher. Understanding of a particular phenomenon within a broader societal complexity requires group or collective reflection to arrive at multiple vantage points from which to view and investigate the different aspects of a topic and at different levels. In this respect diversity of groups become important. The all girls race and class mixed group dealing with the project on time spent after school, through their joint vested interest to address the problem about being given too much homework, came to see how this issue had dimensions of race, class and gender found in 
broader society as they interviewed different members of the community and the classroom and compared each other's data on what they did after school. For instance, they found out that some boys from poor backgrounds did chores after school that were traditionally done by girls.

The critical dimension of mathematical literacy carries an imperative to go beyond investigating and understand the injustices and inequalities in society, but incorporates the imperative for the curriculum to provide the tools for meaningful action to improve social conditions related to learners' lives. Learners' intentions and interests to learn mathematics may be enhanced through an exemplary organising of the curriculum. In this they can come to understand how mathematics can be useful and be used in their interests but also how it can be problematic in dealing with real life problems that have multiple dimensions to them.

\section{Assessment}

In South Africa project work is currently more commonly used as an assessment strategy (Mullis et al., 2000) where it is typically assigned as homework involving small investigations by individuals or small groups. This practice has emerged mainly as a result of the introduction of continuous assessment since the mid '90s. The pedagogy of project work being presented here is somewhat different, regarded as more "progressive" in advocating a more "openedended", "learner-centred" and "activity-based" approach.

Project work makes it possible for learners to see that a problem can be solved in many different ways and gives the possibility for these to be demonstrated with different explanations and justification. The participant directed aspect of project work creates space for negotiating assessments with learners. Agreement can be sought on what aspects of the project, at what time and what will be taken as evidence for assessment. In this conception of project, which is typically undertaken over an extended time as a classroombased activity, assessment can be done on an ongoing basis. Moreover, it allows multiple assessment formats to be integrated - individual, peer and group. The new South African mathematics curriculum allows for teachers to engage the new assessment policies which encourage many of these practices.

If mathematical literacy is conceptualised as an integrated competence then it has to be assessed more broadly both in the different forms of knowing and formats. Assessments often indicate to learners what is being valued in the classroom and by teachers. The different activities that make up project work means that many different activities can be valued in this broader connected conception of mathematics. These include for example: the planning done; the workings of the group as a collective; presentations; broad engagement of topic or problem at different levels; writing reports and other documents; content learned; etc.

Despite these positive possibilities, the issue of assessments in project work has been raised routinely by practitioners who must balance different approaches and assessments imperatives. For instance, the tension between group and individual assessments - the higher weighting and valuing of individual examination scores and the ways in which it is counterproductive for group work is one critique and a tension in project work. The question that came up in the project work is that of why should learners cooperate if what eventually gets most valued is individual performance. Learners within school compete for marks, and for access to further educational opportunities. Another difficulty that may emerge is that the interdisciplinarity aspect requires teachers to have a much broader knowledge of not only mathematics but also have some understanding of societal issues and a range of other disciplines to be able to guide and direct learners to the relevant sources.

\section{Practical organisation}

In this much broader conception of project work involving a "research-like" process, learners are given greater independence in their learning to identify a problem, collect information, analyse and draw conclusions, write reports and present their findings and position on the matter under investigation. The teacher's role becomes one of guiding the process in the role of a facilitator or supervisor. Given that this is the mathematics classroom and learners are expected to learn this mathematics, even as they may go into other subject matter, the teacher cannot renege on the didactical contract between herself and learners to ensure that the necessary mathematics is learnt, albeit a contextualised mathematics. However, the teacher is also a student in listening and learning about what knowledge and skills and values each learner brings into the project by virtue of their having lived particular lives in particular contexts. In the education project, participants became aware of the huge costs in funds and time some parents incurred in travel to send their children to a 


\section{Renuka Vithal}

particular school and the burdens this created for learners who had to rise two hours earlier than other learners, while in the homework project girls from poorer families showed in the calculations done how much time they spend after school in family chores of childminding, cooking, etc., while others participate in extracurricular activities of music and dance lessons. Project work processes and activities give teachers access to background knowledge as well as foreground information, about the dreams and aspirations of learners that can guide their intervention in particular projects.

The interdisciplinary nature of project work creates opportunities and imperatives for groups of teachers to work together in small teams as collectives to deal with different content and skills needed. Depending on the kind of project, the mathematics teachers interacted with language, science and geography teachers. Implementation of this kind of project work could require reorganising some of the practical features of classroom life or in the functioning of schools to facilitate the activities of the project. For instance, a group of teachers could agree to pool their teaching periods to create block sessions for extended work on the project. Further, the classroom can be transformed to simulate a particular environment such as a newspaper office if learners are involved in developing a newsletter to have the experience of being journalists (Nielsen et al., 1999).

Since in this conception of project work, real outcomes in changing some aspect of learners' lives are aimed for, it also means the teacher has to pave the way for learners to meet with some authorities such as the school principal or a local councillor. In the fence building project, the teacher sought to invite a land surveyor to show how grounds are measured and by whom; and in a project on electricity provision the plan included involving the electricity company to explain the different electricity systems being implemented and their different costs. Such projects can also include excursions to different places to give learners first hand real life experiences and interaction with people who do the actual kinds of work they are investigating in the project.

\section{Conclusion}

The presentation of what learners uncover through the activities of the project to people it most affects and involves, makes the mathematics powerful in a different way from that experienced in the traditional classroom only. Even if the entire curriculum is not organised through project work, as is the case in some institutions such as Aarlborg and Roskilde Universities in Denmark (Niss, 2001; Olesen \& Jensen, 1999; Vithal et al., 1995), the opportunity to engage in one project, chosen and undertaken in a way that realises the exemplarity principle, makes it possible for learners to experience and know both the power and limitations of mathematics. Through project work they can learn how to work in diverse groups inside schools and in broader society; and come to see how schools in general but mathematics teaching and learning in particular can provide the curriculum tools to act in their own interests and those of their families and communities to address societal injustices and inequalities.

The conceptual tools, principles and practice discussed here in this form of project work are offered in the spirit of inspiring teachers to experiment and explore in their mathematics literacy classrooms. To take some calculated risks to evolve new and different ways of teaching mathematics to achieve the policy intentions of the new mathematics literacy curriculum that invites for creative possibilities that could be shared and built on.

\section{References}

Bastos, R., \& Costa, F. (2000). Transdisciplinarity and Curriculum Organisation. In J.P. Matos \& M. Santos (Eds.), Proceedings of the Second International Mathematics Education and Society Conference, 26-31 March (pp.169-179). Portugal: University of Lisbon.

Bishop, A.J. (1988). Mathematical Enculturation: A Cultural Perspective in Mathematics Education. Dordrecht: D. Reidel Publishing Company.

Boaler, J. (1997). Experiencing School Mathematics: Teaching styles, sex and setting. Buckingham: Open University Press.

Brown, M. (2003). Research and National Policies in Primary Numeracy. In B. Putsoa, M. Dlamini, B. Dlamini, \& V. Kelly (Eds.), Proceedings of the $11^{\text {th }}$ Annual Conference of the Southern African Association for Research in Mathematics, Science and Technology Education Research, 11-15 Jan. Swaziland: Waterford Kamhlaba.

Christiansen, I.M. (1996). Mathematical Modelling in High School: From Idea to Practice. Revised Doctoral Dissertation. Denmark: Aalborg University.

Department of Education (DOE). (2003). National Curriculum Statement Grades 10-12 (General) 
Mathematical Literacy. Pretoria: Department of Education.

Frankenstein, M. (1987). Critical Mathematics Education: An Application of Paulo Freire's Epistemology. In I. Shor. (Ed.), Freire for the classroom: A sourcebook for liberatory teaching (pp. 180-210). New Hampshire: Boyton and Cook Publishers. (First appeared in 1983 in the Journal of Education, 165(4), 315339.)

Frankenstein, M. (1990). Critical Mathematical Literacy. In R. Noss, A. Brown, P. Dowling, P. Drake, M. Harris, C. Hoyles, and S. MellinOlsen (Eds.), Political Dimensions of Mathematics Education: Action and Critique. Proceedings of the First International Conference (pp.106-113). London: Institute of Education, University of London.

Gutstein, E. (2003). Teaching and learning mathematics for social justice in an urban, Latino school. Journal for Research in Mathematics Education, 34(1), 37-73.

Mellin-Olsen, S. (1987). The Politics of Mathematics Education. Dordrecht: D Reidel Publishing Company.

Mullis, I.V.S., Martin, M.O., Gonzalez, E.J., Gregory, K.D., Garden, R.A., O'Connor, K.M., Chrostowski S.J., \& Smith T.A. (2000). TIMSS 1999 International Mathematics Report: Findings from IEA's Repeat of the Third International Mathematics and Science Study at the Eighth Grade. Chestnut Hill: International Study Center, Boston College.

Nielsen, L., Patronis, T., \& Skovsmose, O. (1999). Connecting Corners: A Greek-Danish Project in Mathematics Education. Aarhus: Forlaget Systime.

Niss, M. (2001). University mathematics based on problem-oriented student projects: 25 years of experience with the Roskilde model. In D. Holton (Ed.), The teaching and leaning of mathematics at university level: An ICMI study. Dordrecht: Kluwer Academic Publishers.

Olesen, H.S., \& Jensen, J.H. (Eds.) (1999). Project Studies - a late modern university reform? Copenhagen: Roskilde University Press.

Paras, J. (1998). Improving the Playground: A Fence-Building Project in Mathematics. Pythagoras, 46/47, 57-62.
Rasmussen, P. (1991). The Role of the First Year in the Educational Structure and Pedagogy in Aalborg University. In A. Lorentson \& A. Kolmos (Eds.), Quality by Theory and Practice of Higher Education: Proceedings from the First European Conference on the First Year Experience in Higher Education. TNP-Series No. 6. Denmark: Aalborg University.

Skovsmose, O. (1994). Toward a Critical Philosophy of Mathematics Education. Dordrecht: Kluwer Academic Publishers.

Skovsmose, O., \& Nielsen, L. (1996). Critical Mathematics Education. In A.J. Bishop, M.A. Clements, C. Keitel, J. Kilpatrick \& C. Laborde (Eds.), International handbook of mathematics education. Dordrecht: Kluwer Academic Publishers.

Steen, L.A. (2001). (Ed.) Mathematics and Democracy: Case for Quantitative Literacy. USA: National Council on Education and the Disciplines, The Woodrow Wilson National Fellowship Foundation.

Vithal, R. (2003). In search of a pedagogy of conflict and dialogue for mathematics education. Dordrecht: Kluwer Academic Publishers.

Vithal, R. (2004). Devan; mathematics; and project work. South African Journal of Education, 24 (3), 225-232.

Vithal, R. (2005). Gender Justice, Human Rights and Measurement in the Mathematics Classroom. International Journal of Mathematical Education in Science and Technology, 36(8), 827-841.

Vithal, R., Paras, J., Desai, S., Zuma, Z., Samsukal, A., Ramdass, R., \& Gcashbe, J. (1997). Student teachers doing project work in primary mathematics classrooms. In P. Kelsall \& M. de Villiers (Eds.), Proceedings of the Third National Congress of the Association for Mathematics Educators of South Africa. July 7 - 11. Durban: University of Natal.

Vithal, R., Christiansen, I., \& Skovsmose, 0. (1995). Project Work in University Mathematics Education. Educational Studies in Mathematics, Special Issue on Advanced Mathematical Thinking. 29, 199-223. 